\title{
EDUARDO L. HOLMBERG Y LA RENOVACIÓN DE LA NOVELA POR LA FANTASÍA
}

\author{
EDUARDO L. HOLMBERG AND THE RENEWAL \\ OF THE NOVEL BY FANTASY \\ Hebe Beatriz Molina \\ Universidad Nacional de Cuyo-Conicet. Mendoza, Argentina. \\ Hebemol@Ffyl.Uncu.Edu.Ar
}

\begin{abstract}
Resumen: El científico y escritor argentino Eduardo Ladislao Holmberg (1852-1937) es pionero en diversas modalidades narrativas, sobre todo el relato fantástico, el policial, la fantasía científica y la ciencia-ficción. En este artículo se analiza cómo renueva la poética de la novela, en un proceso que culmina en La bolsa de huesos (1896). La novedad radica en que Holmberg realza la función creadora de la fantasía en la estructuración del discurso novelístico y, por ende, potencia lo ficcional como elemento sustantivo de la novela, en contraste con las tendencias románticas y naturalistas, que priorizaban lo verosímil moral (la novela como espejo de la sociedad).
\end{abstract}

Palabras clave: Eduardo Ladislao Holmberg, teoría de la novela, poética histórica, fantasía.

\begin{abstract}
The Argentine scientist and writer Eduardo Ladislao Holmberg (18521937) is a pioneer in different narrative genres, particularly fantastic stories, police stories, scientific fantasy and science fiction. This article analyzes how he renews the poetics of the novel in a process ending with La bolsa de huesos (1896). His novelty lies in enhancing the creative function of fantasy in structuring novel discourse, thus maximizing fiction as a substantive element of the novel. This contrasts with romantic and naturalistic tendencies which prioritized what was morally credible (the novel as a mirror of society).
\end{abstract}

Keywords: Eduardo Ladislao Holmberg, theory of the novel, historical poetics, fantasy.

Recibido: 03.10.2016. Aceptado: 27.06.2017 
"iPreceptos! Para preceptos sirvo yo". E. L. Holmberg. Nelly.

\begin{abstract}
Nastasio, periodista de El Álbum del Hogar, el 16 de febrero de 1879, Apresenta una reciente publicación de Eduardo Ladislao Holmberg, científico y escritor argentino (1852-1937):
\end{abstract}

Horacio Kalibang es una produccion sui generis de la inteligencia de su autor: en ella campea la brillantéz y la galanura de la forma literaria, la erudicion científica armonizada con la amenidad digna de las novelas de Julio Verne y todo ello matizado con cierto sabor de crítica que estimula el interés y la curiosidad del lector $(258)^{1}$.

En otros avisos de la misma revista, el texto es anunciado como "una obra de ciencia y de crítica especialmente, que hace honor á su autor" (Anónimo, 1879: 240) y del escritor se dice que es "bastante conocido, como hombre estudioso en materia de ciencias naturales y como amante de la literatura que sale bien en todas sus empresas" (Juan Santos, 1879: 346; Gasparini, 2012: 286-288). Estas afirmaciones importan por dos motivos: por un lado, presentan la personalidad y la escritura original del autor; por otro, señalan la necesidad y la imposibilidad de los lectores-periodistas de asignarle un género al texto. Hay que considerar que, después de un período de floración (década de 1850), la escritura de novelas en Buenos Aires decae en originalidad hacia mediados de los años 70, hasta que con el auge del Naturalismo (1879-1880) el género recobra fuerzas y se diversifica en múltiples modalidades.

La bibliografía sobre Holmberg ha aumentado notablemente en los últimos años, sobre todo a partir de la reedición de sus textos, que han permanecido casi desconocidos hasta el siglo XXI. Gioconda Marún, Enriqueta Morillas Ventura y Rodrigo Guzmán Conejeros, Pablo Crash Solomonoff, Sandra Gasparini y Claudia Román han renovado el esfuerzo editorial que había iniciado Antonio Pagés Larraya en 1957, cuando publicó Cuentos fantásticos. Las narraciones de Holmberg son estudiadas como literatura fantástica, fantasía científica, ciencia-ficción, policial; incluso como novela

\footnotetext{
${ }^{1}$ En esta y en todas las citas respeto la grafía original.
} 
modernista. Los especialistas antes mencionados no dudan en asignarle a cada texto de Holmberg la clasificación genérica de "novela", pero atienden a una modalidad específica en cada caso. Algo similar ocurre en los estudios de Román Setton, Paula Bruno y Carlos Abraham.

Propongo, en cambio, centrar el análisis en el género y, desde la perspectiva de la Poética Histórica ${ }^{2}$, indagar acerca de cuál es el concepto de novela que maneja Holmberg. Defiendo la hipótesis de que este autor reorienta la poética de la novela, pero lo hace de un modo silencioso, es decir, sin escandalizar ${ }^{3}$ a los lectores, en un proceso que culmina en La bolsa de huesos (1896). La clave de esta renovación se halla en la importancia que le asigna a la fantasía como generadora de ficciones y a estas, como elemento primordial del discurso novelístico, en contraste con las teorías románticas y naturalistas, que pretendían una novela moralizadora y espejo de la realidad, según repasaré a continuación.

\section{Poética de la novela hacia fines del siglo XIX}

-¿Has leído la María de Jorge Isaacs? -preguntan con entusiasmo los viejos literatos, saboreando con delicia las mieles del pasado.

-¿Has leído la María? -se preguntan con sonrisa picaresca dos niñas en cuyos rostros se refleja el idilio de la vida.

-¿Has leído la María? - preguntan las matronas cuyos idilios han tomado el tinte de las hojas de Otoño, pero que, semejantes a las del laurel, conservan todo su aroma.

- ¿Has leído la María? - preguntan con los rostros iluminados por los albores del alma, dos modernos Leandros (Marún, 2002: 55).

\footnotetext{
${ }^{2}$ La Poética Histórica estudia la evolución de las estructuras o formas literarias a partir de las modificaciones (excepciones) que se realizan sobre la tradición recibida; presupone que la comunicación literaria solo es posible cuando autor y lector comparten la serie de reglas o normas convencionales que definen la forma y sobre cuya base se gesta la originalidad. En este aspecto, puede asociarse al concepto de repertorio, de la Teoría de los Polisistemas. Por todo ello, este enfoque se centra en la teoría poética vigente en el período estudiado. La poética puede estar explicitada en diversos tipos de textos metaliterarios o puede ser inferida del texto literario mismo (Głowiński, 1976).

${ }^{3}$ Aludo a las acaloradas discusiones que se suscitan en Buenos Aires ante la aparición de la novela naturalista, desde 1879 (Molina, 2013a).
} 
Este es el comienzo de "Clara", la primera novelita ${ }^{4}$ de Eduardo Ladislao Holmberg. Aparece en El Porvenir Literario, de Buenos Aires, en octubre de 1872. A pesar del título, el personaje central es Ricardo, un joven sensiblemente enamorado de Clara. Con sutil ironía, el narrador -materialista- se burla de la pasión irracional de su amigo, especie de Monsieur Bovary, quien cree posible vivir lo que narran las novelas y la poesía. El texto del colombiano sirve de nexo entre los personajes; sin embargo, en Ricardo esa lectura lo incita al "amor hasta la muerte", mientras que para Clara solo es amor hasta que aparece un canadiense acaudalado, con quien luego se casará. Ante este desenlace, el narrador amigo se pregunta: “¿Por qué creí que la lectura de María habría hecho alejar de Clara todo instinto de mezquindad e interés mal entendido?" (60). Sin duda, con esta pregunta, el autor cuestiona la poética de novela que en ese momento opera en el sistema literario argentino.

Desde la década de 1850 escribir novela ha sido una cosa seria, disculpada como producto juvenil, como improvisación, pero con una finalidad civilizatoria bien definida: sociabilizar a los ciudadanos, modelar las costumbres de acuerdo con las normas morales del catolicismo. Y esta misión social, que le asignan tanto los escritores, como los lectores y publicistas, se cumple mediante un discurso narrativo que debe actuar como espejo de la sociedad, en el cual el público debe ver reflejada la realidad social y de sí mismo, a fin de advertir sus propios vicios y modificarlos, y reconocer las virtudes y multiplicarlas. En otras palabras, la novela-espejo sirve para educar y moralizar; si no educa, ni moraliza no vale la pena ser leída. Las reglas indispensables son, pues, la verosimilitud (en tanto mímesis), la moralidad (axiología claramente manifestada en la trama y, sobre todo, en el desenlace) y, en consecuencia, la didacticidad; a las que se suman, como vehículo discursivo, la selección de conflictos de la vida privada, la amenidad, y el lenguaje familiar y corriente (Molina, 2011).

Vicente Fidel López, a quien puede considerarse el primer teorizador literario argentino, en su Curso de Bellas Letras $(1845)^{5}$ ubica la novela

\footnotetext{
${ }^{4}$ Empleo el término "novelita", pues es el que se usaba por ese entonces para denominar las novelas de menor extensión. No operaba todavía la distinción cuento/nouvelle/novela.

${ }^{5}$ Es un manual de retórica y poética preparado para la Universidad de Chile. Está escrito en la denominada "ortografía americana". Se usaba también en la Universidad de Buenos Aires hacia 1870.
} 
entre los textos poéticos y la define como "la idealizacion de un suceso doméstico, narrada con tono sencillo i vulgar; para interesar la imajinacion, promover afectos morales, i fortalecer los buenos principios de nuestra conducta privada" (1845: 297). Otra novedad de este manual consiste en la valoración de la fantasía, elemento literario ausente en los otros tratados de retórica y poética de lectura obligatoria por ese entonces. La fantasía es considerada como una de las tres facultades mentales básicas -las otras dos son la razón y la memoria- que permiten clasificar los escritos en textos filosóficos, históricos y poéticos. Además, López explica detenidamente la verosimilitud como un efecto del estilo. Insiste en que el autor debe equilibrar dos requisitos: por un lado, que el asunto no sea cierto, sino creación ideal de la imaginación; y, por otro, que "se reconozca la posibilidad racional" de que sea cierto, o sea, que el oyente o el lector pueda establecer fácilmente las analogías entre la realidad y la creación imaginaria. Y sintetiza la regla fundamental: "Ficcion i analojía de esa ficcion con la realidad- e aquí la léi fundamental de las obras de fantasía" (117; Molina, 2008).

Esta poética de la novela se repite más o menos explícitamente en distintos paratextos, sobre todo durante la polémica entre Romanticismo y Naturalismo, cuando se debaten abiertamente cuestiones de forma y de contenido. Las conferencias y los artículos periodísticos publicados en ese contexto demuestran que, a pesar de las posturas antinómicas a favor o en contra del modelo importado de Francia, la teoría de la novela no sufre cambios significativos durante las últimas décadas del siglo XIX (Molina, 2013b).

Como ejemplo y para ayudar a entender las ironías de Holmberg, tomo un artículo del colombiano Adriano Páez ${ }^{6}$ (1870), aparecido en la Revista Argentina y referido a María, texto que está siendo publicado al mismo tiempo en esa revista7. El amigo de Jorge Isaacs elogia la novela porque lo ha conmovido y la causa de tal conmoción son sus dos cualidades principales: la verosimilitud y la moralidad. La primera, entendida como "fidelidad, ó mejor dicho, la verdad en la descripcion de caracteres y costumbres"

\footnotetext{
${ }^{6}$ Adriano Páez (1844-1890) es un escritor, periodista y político colombiano; incluido en el Parnaso colombiano: Colección de poesías escogidas por Julio Añez (1886).

7 "Maria (novela orijinal)" comienza a aparecer en el tomo IX (1870, pp. 16-38, 97-123, 207-244, 289-322, 445-458, 501-537), continúa en el tomo X (1871, pp. 5-33, 97-122, 289$328,441-470,487-506)$ y concluye en el tomo XI (1871, pp. 5-31).
} 
(253), expresa la regla del espejo, aun cuando Páez reconozca que María es creación y no copia servil (254). Lo verosímil se afirma en la capacidad de la palabra literaria de volverse imagen ("supieron no solo escribir, sino pintar; sus obras son cuadros”, 253) y tan bien imaginables son los caracteres, ambientes y costumbres que traen a la memoria reminiscencias personales: "conmueve. MARía es el libro de los recuerdos" (252). Esta cualidad refuerza la otra regla: "Tiene tu obra moralidad" (255). Si en décadas anteriores la exigencia de trama narrativa moral tenía basamento en la necesidad de configurar la imagen de una nueva nación, hacia 1870 el requisito se afianza en la lucha declarada contra la supremacía de la teoría positivista y por la comparación con el Naturalismo en ciernes: "Porqué hemos de venerar á esos que ensalzan el materialismo, revisten de flores el esqueleto de la duda y divinizan las mas innobles pasiones? Jénios mortíferos, matan las almas”. Si bien Páez apunta al contenido, no se preocupa menos por la seducción que ejerce la novela como texto ameno y atractivo para todos, incluido el propio comentarista:

Y esa literatura materialista y falaz es la que busca la juventud, sedienta de emociones! $\mathrm{Y}$ en esas aguas de limpia superficie y seno asqueroso hemos bebido todos con delicia! Y con delicia tragamos el veneno, y este vá infiltrándose en el alma, causando una desorganizacion moral prematura; porque el materialismo solo puede dar frutos de asquerosa corrupcion (255).

La infiltración ideológica es, pues, el gran peligro social que origina la novela por su naturaleza genérica: narración de hechos verosímiles tan amena que puede no solo conmover, sino sobre todo seducir e imponer tanto valores supremos, como disvalores inadmisibles. Páez concluye con una definición previsible: "Tu libro es la epopeya del amor cristiano" (256). Juicios similares contra el Naturalismo se oirán de boca de escritoras e intelectuales católicos, como Juana Manuela Gorriti, Eduarda Mansilla de García, José Manuel Estrada, Santiago Estrada, Mariano Pelliza y Carlos Bigot (Molina 2013a).

Pero no es la axiología religiosa el verdadero meollo de la discusión, sino el grado de verdad en la representación novelesca; por eso, las objeciones a la novela no diferencian lo romántico de lo naturalista. Mariano Pelliza, enmascarado tras el seudónimo de "Cora Olivia", supuestamente 
una argentina que ha vivido algunos años en Europa, escribe unas "Conversaciones literarias” en La Ondina del Plata, en julio de 1877, es decir, al año siguiente de que en esa revista Holmberg publicara "El ruiseñor y el artista”. En ellas expresa su poética de la novela a partir de las condiciones que le impone al género:

Cuando esas producciones artificiales del ingenio [las novelas], resultado enfermizo de cerebros mas enfermos aun, no expresan siquiera un principio de moral doméstica, no tienen por fin realzar la virtud ó combatir el vicio, carecen de significado en las funciones lógicas del espíritu ennoblecido por la civilizacion (299);

Es un hecho averiguado que la novela llamada de fantasía ó romántica, destinada á pintar los caracteres externos de la sociedad, no merece ninguna consideracion, porque nada enseña, á no ser aquello que no debe saberse por cierta clase de lectores y lectoras; y solo cuando se asocia con talento á la historia[,] el arte ó la ciencia, obtiene el sufragio de la gente de buen gusto (300-301).

Obsérvese que la expresión "llamada de fantasía ó romántica” implica la idea de que este tipo de novela idealiza de tal modo los personajes que estos parecen irreales y sus acciones, inverosímiles. En otras palabras: las novelas no cumplen la norma didáctica si no están asociadas con otros saberes y producciones de mayor calidad, que limiten la natural tendencia de la fantasía a producir desbordes (desbordes que no ocurren en "gente de buen gusto", bien educada).

En cuanto al comentario de Pelliza acerca de la recepción, remito a Fabio Espósito, quien analiza los distintos tipos de lectores de novelas que aparecen representados en las propias novelas publicadas en las últimas décadas del siglo XIX; por ejemplo, el lector romántico y enfermo (o descontrolado) de María gracias a los personajes de Amar al vuelo (1884), de Enrique E. Rivarola, y Alma de niña (1903), de Manuel T. Podestá. Espósito concluye:

En estas escenas es posible reconocer un solapado debate en torno a los distintos modelos de lectores: el tradicional miembro de un público selecto depositario de una cultura política basada en el cultivo de la virtud y del talento, para quien las lecturas literarias y la afición a las letras complementan su formación de político literario, que concibe la práctica de la escritura como un ejercicio más de su carrera política; el lector que 
se vuelve novelista, que lee con otra moral y con otros propósitos; la imagen preocupante y problemática de los nuevos lectores, entre los que se destaca la figura amenazante de la mujer lectora de novelas (2009: $201)^{8}$.

Los promotores del Naturalismo no discuten el objetivo de la novela como formadora porque insisten en su característica de espejo de la realidad; solo modifican algunas reglas: agregan el respaldo del rigor científico y la aparente objetividad del narrador. Cambian los modos de reflejar la sociedad: del espejo cóncavo del Romanticismo, al espejo convexo del Naturalismo, pasando por el espejo plano del Realismo (Molina, 2013a). No es extraño, pues, que también los naturalistas usen la metáfora de la pintura para representar la cualidad esencial del discurso novelesco. Se mantiene, además, la misión asignada al género: exponer lo bueno y lo malo para cuestionar, modificar, mejorar la realidad extratextual. Nuevamente, por esa función educativa se rechaza la exuberancia de la imaginación. Benigno Lugones pone límites a la ficción novelesca al hablar de fotografía: "El naturalismo se propone pintar la realidad, sin quitarle ni ponerle, tal cual es la vida, tales como son las cosas; las producciones naturales son una fotografía y deberán retratar lo malo y lo bueno, lo sucio y lo limpio, lo atrayente y lo repugnante" (2011: 17). Luego explicita: "Hoy diremos la verdad, nada más que la verdad, a fin de que la literatura responda mejor que en ninguna otra época a su fin de utilidad” (19). En la misma línea, el médico italiano Luis Tamini aclara: "románticos y naturalistas no pueden más que imitar: la diferencia que hago entre unos y otros es que estos consiguen acercarse más a la verdad" (2011: 38). En definitiva: la novela debe fotografiar la realidad, repetirla o imitarla, para ser útil y la utilidad consiste en difundir la verdad. Ante tales exigencias, parece inviable la regla de la ficción.

Los prejuicios contra la fantasía son mayores en los naturalistas porque la consideran culpable de males sociales, como el mantener en la ignoran-

\footnotetext{
${ }^{8}$ No comparto, en cambio, la postura de Espósito respecto de que la novela argentina emerge hacia 1880 , cuando los -en mi opinión- mal llamados "primeros novelistas" cultivan el género "con cierta continuidad" debido a "los modos de intervención de un sector de la prensa partidaria porteña” (2009: 199). Considero que la larga lista de novelistas y títulos que aparecen entre 1838 y 1880 justifican anticipar la emergencia de la novela argentina y responsabilizar de tal fenómeno a los escritores de la Generación de 1837 (Molina, 2011).
} 
cia, y de trastornos psíquicos, como el tan temido bovarismo, femenino o masculino, que conduce generalmente al suicidio. Dorotea y su hijo José, personajes de ¿̇Inocentes o culpables? (1884), de Antonio Argerich, son dos tipos representativos de esta doble problemática. El narrador de esta novela, como el de todas las de esa época, juzga la conducta de los personajes -el título es ilustrativo al respecto- y explica las razones que, en su opinión, carcomen la sociedad:

[Dorotea] Estaba perdidamente enamorada del militar y no le conocia. Prueban en fisiología que cuando un miembro está atrofiado ó no funciona, los otros adquieren mayor desenvoltura y precision.

Lo propio sucede en la sociedad moderna con las facultades morales. Mientras el juicio duerme, la imaginacion, siempre en juego, alcanza proporciones colosales.

Ella obra sin contrapeso y mantiene á la inteligencia en un eterno espejismo.

Dorotea se engañaba al creer que amaba al Mayor: todo el entusiasmo de su alma se lo prodigaba entero, sin saberlo, á Rocambole, á Romeo, y á toda la caterva de héroes que habia conocido en las novelas románticas [...] (1984: 116).

Es sabido que la novela naturalista o experimental se propone imitar el análisis metódico de la realidad, como lo hacen las ciencias naturales principalmente. El propio Argerich, en el prólogo, expone su tesis sociológica - "me opongo franca y decididamente á la inmigracion inferior europea" (1984: 10)- y sus pruebas basadas en hechos y datos estadísticos, ya que su novela "no reposa en un castillo de naipes", sino en un estudio "de las causas que obstan el incremento de la poblacion" $(15,9)$. No obstante, cae en la simpleza de la vieja dicotomía romántica: inteligencia o razón (que asegura la moral de las conductas) versus imaginación (que engaña).

Interesa recordar también que la palabra "fantasía" empieza a ser usada como sinónimo de novela hacia la década de 1870. Anteriormente, aparece denominando textos líricos en prosa, efusivos, sin narración; por ejemplo: Fantasía (1857), de Laurindo Lapuente, y "Fantasia”, de "Eufrátes" (en La Ondina del Plata, 1875). Luego y ante las exigencias positivistas y cientificistas respecto de las pruebas y credibilidad de los datos, la novela que no tiene fundamento en una realidad inmediata (referencial), sobre todo la gótico-fantástica, es apodada de tal modo; en tanto que el adjetivo que 
modifica su sentido -fantasía científica, fantasía espiritista- se refiere al tema ${ }^{9}$.

\section{La fantasía y los juguetes literarios de Holmberg}

Holmberg se suma a la defensa de la novela naturalista pues la asocia con la ciencia. En La bolsa de huesos lo hace explícitamente, cuando el narrador novelista explica a su amigo Manuel en qué consiste su novela:

... se trata de la aplicación de los principios generales de la medicina legal, que es una ciencia, y de demostrar que la ciencia puede conquistar todos los terrenos, porque ella es la llave maestra de la inteligencia. La ciencia conquistará al hombre, que no han conquistado aún la religión ni la política. 'La novela -me decía no ha mucho uno de mis amigos más espirituales- es la epopeya moderna en prosa'. Y bien, sí. Y la epopeya es la ciencia de la antigüedad. El templo más esplendoroso que tuvo Minerva fue el cerebro de Homero (1957: 233) ${ }^{10}$.

Según Holmberg, entonces, la novela es o puede equivaler a la ciencia moderna como llave maestra de la inteligencia. Esta igualación se origina en el concepto de fantasía que maneja el autor: capacidad de la inteligencia que permite "arrancar a la verdad todas sus formas" (2001: 10), sea a través de la ciencia, sea a través de la literatura y el arte (Guzmán Conejeros) ${ }^{11}$. Por

\footnotetext{
${ }^{9}$ Algunos títulos que muestran la imprecisión genérica: Almanaque de Orión: Novelas, cuentos, fantasías, historias, anécdotas (1875), de Héctor Florencio Varela; Panoramas de la vida: Colección de novelas, fantasías, leyendas y descripciones americanas (1876), de Juana Manuela Gorriti; El Doctor Whuntz: Fantasía (1880), de Raúl Waleis (seudónimo de Luis V. Varela), "La cruz de brillantes (Fantasía)" y "La tumba del vampiro (Fantasía)", de Matilde Elena Wilt (en Alborada Literaria del Plata, 1880); El César: Fantasía (1882), de Josefina Pelliza de Sagasta; Novelas y fantasías (1888), de Roberto Payró.

${ }^{10}$ Lo más probable es que el amigo sea Vicente Fidel López, quien en el Curso de Bellas Letras, antes mencionado, hace suya una definición de Abel-François Villemain (Cours de Littérature Française) y considera la novela o romance como "el poema épico de las naciones modernas" (López, 1845: 295).

${ }^{11}$ Guzmán Conejeros y Gasparini, especialmente, han analizado cómo Holmberg emplea la ficción para transmitir conocimientos científicos. Por su parte, Bruno lo ubica en la historia cultural y destaca su originalidad explicando que sus apreciaciones de la sociedad argentina "no están encorsetadas de manera rígida por matrices comteanas, darwinianas, spencerianas o lebonianas... Es decir, aunque sumó elementos científicos a varias piezas literarias, no fue un médico que insertó el bisturí sobre el cuerpo social ni un naturalista que miró desapasionadamente a la sociedad, intentando clasificar y atribuir funciones regulares a cada elemento" (2011: 182).
} 
ello, es indispensable para divulgar conocimientos científicos: "En nuestros tiempos, las ideas serias no cumplen su destino sino envueltas en el manto de la fantasía" (Holmberg, 2006: 32). Aún más, en Olimpio Pitango de Monalia, después de destacar la importancia primordial de los cuentos para la educación completa de los niños (1994: 181), afirma: "la imaginación y la fantasía... son las energías motrices de la ciencia y de los descubrimientos" (1994: 190).

Además de esta asociación entre facultad creadora y divulgación científica, Holmberg acrecienta la importancia de la fantasía cuando emplea el término como subtítulo en dos narraciones -Dos partidos en lucha: Fantasía científica y Viaje maravilloso del señor Nic-Nac [al planeta Marte]: Fantasía espiritista (ambas de 1875) - y, sobre todo, cuando caracteriza a algunas de sus novelas como "juguetes", en los que lo ficcional se fusiona con lo lúdico. En esta serie se observa cómo el escritor se aparta de las convenciones más distintivas de la poética de la novela dominante en el sistema literario de ese entonces.

El primer "juguete literario" es el "paquete de manuscritos" que Ladislao Kaillitz le deja a Eduardo Ladislao Holmberg, autor ficcionalizado, y que este se presta a leer "con esa avidez del que lee por conocer el argumento de una novela" (Dos partidos en lucha; 2005: 43). Obsérvese este dato: una novela tiene un argumento que atrae al lector como con un imán. El lector es cómplice necesario para que el texto sea juguete. Un lector real de esta publicación comenta en La Ondina del Plata que lo cree "un trabajo de mérito. Escrito para promover la hilaridad es á la vez instructivo, por que él vulgariza la ciencia" (Anónimo, 1875: 83). Las "Dos palabras" preliminares de Holmberg (¿autor o ficción?) terminan con una aclaración interesante: muchas ideas están expresadas "en el lenguaje de la palabra presentida" pues "en todas las obras del ingenio humano hay un más allá que, como dice nuestro amigo el poeta Rafael Obligado / Se sueña, se presiente, se adivina..." (2005: 44). Entonces, esta obra pensada para vulgarizar la ciencia abarca también consideraciones sobre eso invisible que corre los márgenes del conocimiento más allá de lo racional y de lo sensible, es decir, sobre la fantasía como capacidad humana.

El segundo juguete es Horacio Kalibang o los autómatas. Holmberg dedica "este juguete discutible" a José María Ramos Mejía, médico dedicado a las enfermedades mentales. En esta novela no hay debate científico, 
como en la anterior, sino la ciencia del futuro puesta en acción. La trama se organiza sobre la base de varias incógnitas que se van develando hasta llegar a la conclusión de que casi todos los personajes son autómatas. Al comienzo hay un narrador que, por ser "fiel retratista", inicia el relato con un diálogo y, por ende, demora la introducción tradicional con la presentación del protagonista, "con toda la solemnidad que el personaje y el lector merecen" (1957: 148). Y termina otro narrador dándole al lector la posibilidad de decidir la interpretación del desenlace: "El lector tocará los demás resortes" (167). ¿Los resortes de los autómatas o los resortes de la trama hacia el desenlace?

El tercer texto de la serie es La bolsa de huesos, de 1896. Un médico científico busca, a partir de la observación de una coincidencia, la verdad escondida detrás de dos esqueletos a los que les falta la cuarta costilla izquierda: múltiples asesinatos a manos de una neurótica.

Marún (1984) y Setton (2012) coinciden en analizar que este texto rompe el modelo de la novela policial o detectivesca porque el asesino, mejor dicho, la asesina -Clara (otra Clara) - no es enviada a la cárcel y, por tanto, no se reinstaura el orden de justicia; mucho más teniendo en cuenta que Clara ha matado, por venganza, a dos buenos jóvenes. Holmberg plantea una serie de problemas científicos y epistemológicos, como los relativos a la frenología y la psicopatología; sobre todo, pretende hacer comprender que la neurosis es un problema de salud mental, que no tiene solución, para el que nada sirven los manicomios y mucho menos la cárcel, cuando el neurótico, por su obsesión, se convierte en homicida. No es el engranaje delictivo el que cautiva al autor, sino el social. En una carta, titulada "Policianas I. Sr. D. Belisario Otamendi”, el escritor -además de reconocer su interés por la literatura policial, que lo ha llevado a escribir La casa endiablada, Nelly y La bolsa de huesos, y su admiración por el escritor francés Émile Gaboriau - confiesa: "No es ahora la fantasía lo que me llama; es la realidad" (Marún, 2007: 524).

Sin embargo, en La bolsa de huesos agrega un elemento novedoso: no solo ficcionaliza cuestiones científicas, sino que ficcionaliza el arte de componer una novela, coartada a través de la cual enmascara la investigación. El médico narrador interroga al señor Equis sobre el origen del primer esqueleto. Apenas el interlocutor pregunta si sospecha de un "crimen misterioso" o si la investigación tendrá "proyección policial” (1957: 184), el 
pesquisidor anuncia que piensa escribir una novela con la información que está recogiendo. Los datos "dan verdad a la cosa" (184). Los hechos tienen una "lógica inflexible" (169), por lo que parecen independientes del narrador, al tiempo que se genera una expectativa que atrae al otro personaje, convertido en lector modelo: "estoy perplejo, y no sé si en este momento me envuelve usted con la realidad o con la ficción"; "Usted me horroriza con su novela. -Pero usted se va interesando" (185). El doctor Equis empieza a intuir la verdad -qué ha sucedido con Mariano (uno de los esqueletos) y con el huésped enigmático (luego sospechoso)- porque la narración, que da pistas sobre las relaciones posibles entre los datos, atrae la curiosidad y la imaginación acerca de lo que ha pasado. La novela se vuelve un modo fascinante de conocer; no obstante, el narrador pone límite a la curiosidad y a la presunción diciendo que es propio de la novela el mentir. Otro límite fundamental se genera cuando intuyen que puede haber más muertos:

-iSi fueran esos los únicos!

Allí nos detuvimos.

Una pregunta más, y la novela perdía su carácter de tal (193).

El médico novelista no deja que la realidad se cuele en la ficción. Quiere manejar los hilos de la trama más libremente y, en definitiva, decidir el desenlace: salvar de la prisión a Clara e incitarla al suicidio como única forma de liberación. Libera así, al mismo tiempo, a la novela de la sujeción a la norma moral. Ante Manuel reconoce: "Pero soy yo quien hace la pesquisa, como novelista, como médico, con espíritu romántico -la mujer me interesa, y me propongo salvarla- y la salvo, es decir, la salvo de la garra policial; pero para eso es necesario que tome una dosis doble de veneno" (231).

La forma también es liberada: es un espejo roto deliberadamente por el novelista. Cada lector puede tipificar el texto como le parezca más conveniente, según como lo haya leído:

-Y entonces ¿̇cómo se va a publicar su novela?

-Muy sencillamente: desfiguro los nombres, modifico los hechos, dejo la trama, y permito que cada cual le dé el nombre que quiera. Unos dirán que es novela, otros que es cuento, otros narración, algunos pensarán que es una pesquisa policial, muchos que es mentira, pocos que es verdad (232). 
Lo mentiroso, lo fingido, eso es la ficción -para muchos- durante el siglo XIX. Para Holmberg, empero, es un componente esencial de la novela. Por ello, en la "Dedicatoria" al comisario Otamendi, destaca que su "juguete policial" ha logrado un "éxito" jamás pensado por el escritor: el lector Otamendi propone "llevar a la cárcel un fantasma de novela" (170). Sin embargo, paradójicamente, el Holmberg prologuista, quien considera que su personaje es ficción, insiste en que es él quien realiza la pesquisa. Parece caer en su propia trampa: ¿investiga realmente a personajes ficticios?

¿Trampa o estrategia narrativa? Holmberg recurre a diversos enmascaramientos para posicionar la ficción y, por consiguiente, la novela. Uno de ellos es presentar los efectos de la fantasía como una "idealidad extraña", entre superstición y misticismo, que le trae a la memoria un texto poético, un fragmento de La cautiva (1837), de Esteban Echeverría, vate romántico, recordado con frecuencia por ese entonces ${ }^{12}$ : "Las armonías del viento / dicen más al pensamiento / que todo cuanto a porfía / la vana filosofía / pretende altiva enseñar"13 (Holmberg, 1957: 174).

Esas armonías del viento, aparentemente, distraen al narrador-protagonista de su trabajo científico y lo conducen a preguntarse por la bolsa de huesos. La imaginación lo impele a resolver el enigma y lo guía en la investigación. Esa "idealidad extraña" se le aparece cuando está describiendo una "gruta, en la que sólo debía intervenir la severidad del geólogo, y no los fantaseos del poeta": "Establecióse una lucha entre las acciones de la razón, de la voluntad y del lirismo, y comprendí que el numen científico me abandonaba" (174). Cambia, pues, el objeto de estudio -aun cuando terminará analizando la gruta de la mente y personalidad de Clara-, pero no el método investigativo. Y el método impulsa la acción y estructura la trama narrativa.

\footnotetext{
${ }^{12}$ Juan María Gutiérrez publica sus obras completas entre 1871 y 1874 . Tamini lo propone como modelo de artistas en un artículo sobre el Naturalismo. Y Rafael Obligado, que ha inspirado a Holmberg en Dos partidos en lucha, dedica al vate romántico la primera de sus Poesías (1885). El pasaje que Holmberg transcribe pertenece al canto I, "El desierto", del emblemático poema de Echeverría.

${ }^{13}$ En Viaje maravilloso del señor Nic-Nac, Holmberg también cuestiona ácidamente el quehacer filosófico: "Nada más lastimoso que la ignorancia humana. [...] Así los filósofos, careciendo por completo de los últimos elementos de investigación, concentran su espíritu y aparentan explicar los fenómenos del universo por cualquier capricho de la imaginación, cual si se tratara de resolver una cuestión abstracta, único caso en que es permitida semejante concentración" (2006: 35).
} 
A las armonías del viento se suman luego "el grito estridente" y la "imagen fugitiva" de una lechuza sobre la bolsa de huesos. Una lechuza, el emblema de Minerva, la diosa que tiene el templo más esplendoroso en el cerebro de Homero (233), como ya se ha comentado. Y si la novela es la epopeya moderna, la lechuza simboliza el motor que impulsa la acción de novelar. La razón no es dejada de lado; por el contrario, permitirá el avance lógico de la trama, asentada en una investigación de tipo policial, pero será la imaginación fantástica la que configurará un discurso novelesco atractivo para los lectores.

Esa reacción intensa ante lo ficcional (las armonías del viento y la lechuza) que experimenta el narrador protagonista explica el sentido de los dos últimos capítulos, esos que cuestiona el lector Otamendi. Es claro que no se requieren para la resolución del caso policial porque el narrador se ha encargado de aportar los indicios necesarios a fin de que todo hábil lector llegue a la conclusión precisa: que una mujer neurótica, por despecho, llega a matar a tres estudiantes de Medicina mediante un veneno vegetal - “Cryptodynama purpúrea” (227)- todavía desconocido para la ciencia ${ }^{14}$. En cambio, para develar la poética de la novela de Holmberg, los capítulos VII y VIII son fundamentales. En ellos se explicita cómo la mujer ha actuado bajo el disfraz de Antonio Lapas ${ }^{15}$. Clara, la verdad que se quiere develar, es conocida a través de una máscara, el discurso novelesco, que fija la atención del lector gracias al poder seductor del suspenso narrativo.

La verdad del arte es bella. El propio narrador médico revela que lo han fascinado, de Clara, no solo sus conocimientos bioquímicos, sino también

${ }^{14} \mathrm{El}$ veneno no es totalmente inventado por Holmberg. El nombre aporta indicios interesantes. La primera palabra está compuesta a partir de dos términos griegos: kryptós, 'oculto, secreto', y dynamis, 'fuerza, capacidad, poder'; la segunda remite al nombre científico de una planta: la Digitalis purpurea, dedalera o digital, cuya flor y hoja contienen una poderosa toxina que afecta el funcionamiento cardíaco y que puede ocasionar la muerte si se la consume en exceso. Era usada, sobre todo, contra las arritmias desde finales del siglo XVIII. En síntesis: “Cryptodynama purpúrea" significa 'poder oculto en la dedalera'.

${ }^{15}$ De esta actuación puede inferirse que Lapas es un apellido simbólico de la obsesión compulsiva del personaje ya que la lapa es un molusco que se adhiere fuertemente a las rocas y, por ende, suele denominarse de ese modo a una persona excesivamente insistente. También puede haber un juego semántico entre el apellido Lapas y la Arctium lappa (lapa, bardana, lampazo), planta herbácea medicinal, cuyas flores son de un color púrpura intenso y poseen brácteas con forma de gancho; también el fruto tiene garfios, gracias a los cuales se adhiere a los animales y así se difunde. 
su belleza: "iQué soberana belleza vieron mis ojos asombrado!" (223); o sea: la ciencia y el arte. Pero es el narrador novelista el que impone las reglas:

-Le he dicho que se mude ese traje. Yo quiero hablar con la mujer, con toda la mujer; quiero leer en sus grandes ojos negros la impresión de mis palabras. iYo lo quiero!

Rendida o sugestionada, obedeció (223).

La novela se rinde a los pies del autor porque este ha descubierto su secreto: por ser ficción, es un discurso que se relaciona dualmente con la realidad. No puede ser una fotografía, ni solo una idealización. Como Antonio Lapas, quien con delicadeza y mucho misterio ha cautivado a jóvenes inteligentes, la novela es la máscara que atrae con su "perfume extraño"; en este sentido, Lapas resulta anagrama de Palas (Atenea). Como Clara, es esa verdad seductora que tanto anhela el hombre alcanzar. La novela consiste, pues, en el medio por el cual la fantasía permite develar los misterios de la naturaleza humana, corre los límites de la racionalidad llevando la mente más allá, pero que requiere de la ficción para que ese develamiento sea atractivo $\mathrm{y}$, por ende, promueva la lectura ${ }^{16}$.

El narrador novelista termina reconociendo que su "corazón artístico se estremece todavía al recordar la belleza de Clara" (235) y se jacta al pensar que esa experiencia causará envidia en los jueces; de inmediato, se distancia de la realidad jugando con el rasgo esencial de la novela, la ficción, que no es -decididamente- ningún espejo:

Pero no es verosímil.

Un juez envidioso solamente puede figurar en una novela.

Éstas son fantasías (236).

La novela, como obra artística, tiene sus propias reglas de coherencia: el narrador no es una persona del mundo real, no tiene que rendir cuentas a nadie por el entramado de hechos; puede, incluso, equivocarse, como

16 "Puede considerarse la divulgación científica como el núcleo de su actividad, como el resumen y el centro neurálgico de sus variados emprendimientos intelectuales" (Abraham, 2015: 192). 
cuando el médico investigador no imagina que, en el relicario de rubíes, Clara guarda el retrato de su hijo. "Por eso es un inconveniente grave el dejarse subyugar por las armonías del viento cuando canta en la ventana" (236). A pesar de este peligro o por esto mismo, Holmberg se ha enamorado de la novela como género, casi sin darse cuenta.

\section{Conclusiones}

Eduardo Ladislao Holmberg otorga especial importancia a la fantasía como capacidad humana para conocer la verdad y, en consecuencia, como instrumento eficaz incluso de la ciencia. Realiza, por tanto, el movimiento opuesto a la novela naturalista: si esta introduce la estructura del experimento y la investigación en la trama novelesca, aquel -en cambio- novela (fantasea) conocimientos científicos para que estos sean interpretados por los lectores. Pero su novedad no se limita a divulgar la ciencia a través de un texto literario.

Holmberg renueva la poética de la novela porque centra la trama en el acto mismo de novelar, juega con el lector (lo ficcionaliza como personaje, le genera intrigas, lo seduce, pero sin obligarlo a pensar de un modo determinado), rompe el espejo cuando logra la verosimilitud interna de la historia narrada sin apelar a la referencialidad externa, deja de lado el requisito tradicional de la moralidad (el narrador incita al suicidio al personaje central) y, sobre todo, subsume lo científico (garantía de verdad) a lo poético-artístico, dándole a la fantasía el mismo estatus que el de la inteligencia y un lugar preponderante en la configuración ficcional de la novela. En síntesis: establece nuevas reglas para el género, gracias a las cuales se encamina hacia la Modernidad.

\section{Referencias}

Abraham, C. (2015). La literatura fantástica argentina en el siglo XIX. Buenos Aires: Fundación CICCUS.

Anastasio (1879, 16 de febrero). Horacio Kalibang. El Álbum del Hogar, 33, 258-259. 
Anónimo (1875, 21 de febrero). Dos partidos en lucha (Fantasia científica). La Ondina del Plata, 3, 83 .

Anónimo (1879, 26 de enero). Crónica de la semana. El Álbum del Hogar, 30, 240.

Argerich, A. (1984). ¿Inocentes o culpables? Madrid: Hyspamérica.

Bruno, P. (2011). Pioneros culturales de la Argentina: Biografías de una época. Buenos Aires: Siglo Veintiuno Editores.

Espósito, F. (2009). La emergencia de la novela en Argentina: La prensa, los lectores y la ciudad (1880-189o). La Plata: Al Margen.

Gasparini, S. (2012). Espectros de la ciencia: Fantasías científicas de la Argentina del siglo XIX. Buenos Aires: Santiago Arcos Editor.

Głowiński, M. (1976, winter). Theoretical Foundations of Historial Poetics. Trad. al inglés de B. Braunrot. New Literary History, 7(2), 237-245.

Guzmán Conejeros, R. (2011). Teoría estética y teoría científica en Holmberg: convergencias y divergencias. XV Congreso Nacional de Literatura Argentina; 1, 2 y 3 de julio de 2009 (pp. 275-281). Córdoba: Facultad de Filosofía y Humanidades, Universidad Nacional de Córdoba.

Holmberg, E. L. (1957). Cuentos fantásticos. Estudio preliminar de Antonio Pagés Larraya. Buenos Aires: Hachette. . (1994). Olimpo Pitango de Monalia: Edición príncipe. Edición, introducción y notas de Gioconda Marún. Buenos Aires: Ediciones Solar.

L. (2001). El tipo más original y otras páginas. Edición, notas y posfacio de Sandra Gasparini y Claudia Román. Buenos Aires: Simurg. . (2005). Dos partidos en lucha: Fantasía científica. Introducción y selección de apéndices de Sandra Gasparini. Buenos Aires: Corregidor. . (2006). Viaje maravilloso del señor Nic-Nac al planeta Marte. Estudio preliminar de Pablo Crash Solomonoff. Buenos Aires: Biblioteca NacionalEdiciones Colihue.

Juan Santos (seudónimo de Martín García Mérou) (1879, 4 de mayo). Crítica literaria. El Álbum del Hogar, 44, 345-347.

López, V. F. (1845). Curso de Bellas Letras. Santiago de Chile: Imprenta del Siglo.

Lugones, B. B. (2011). Carta literaria. En Espósito, F., García Orsi, A., Schinca, G. y Sesnich, L. (eds.), El naturalismo en la prensa porteña: Reseñas y polémicas sobre la formación de la novela nacional (1880-1892) (pp. 17-20). La Plata: Universidad Nacional de La Plata. E-book disponible en http:// www.memoria.fahce.unlp.edu.ar/libros/pm.24/pm.24.pdf.

Marún, G. (1984). La bolsa de huesos: un juguete policial de Eduardo L. Holmberg. Inti: Revista de Literatura Hispánica, 20, 41-46.

. (2002). Eduardo L. Holmberg: Cuarenta y tres años de obras manuscritas e inéditas (1872-1915); Sociedad y cultura de la Argentina moderna. Madrid-Frankfurt am Main: Iberoamericana-Vervuert. 
. (2007). Carta inédita de Eduardo L. Holmberg revela el proceso genético de La bolsa de huesos. Boletín de la Academia Argentina de Letras, LXII, 503-524.

Molina, H. B. (2008). Una poética argentina de la novela: Vicente Fidel López (1845). Hofstra Hispanic Review, 8/9 (Summer/verano-Fall/otoño), 18-32.

. (2011). Como crecen los hongos: La novela argentina entre 1838 y 1872. Buenos Aires: Teseo.

. (2013a). Escritoras ante el escándalo de la novela naturalista (Buenos Aires, década de 1880). Cuadernos del Sur - Letras, 43, 183-200.

. (2013b). Novelas decimonónicas en el margen: Una revisión desde la poética histórica. Gramma XXIV, 50, 28-48.

Páez, A. (1870). Crítica de "Maria” por Jorje Isaacs. Revista Arjentina, IX, 251257.

Pelliza, M. (“Cora Olivia”) (1877). Conversaciones literarias: La novela. La Ondina del Plata, 26, 27, 29, 30, 32 (1 de julio a 12 de agosto), 299-301, 311324, 338-340, 349-352 y 377-378.

Revista Arjentina (1868-1871). Buenos Aires: Imprenta Americana.

Setton, R. (2012). La bolsa de huesos: ¿narración policial o novela corta de artista? Medicina, travestismo y justicia poética. Hápax, 5, 51-64. Disponible en http://www.revistahapax.es/V/Hpx5_Art4.pdf.

Tamini, L. B. (2011). El naturalismo (Segunda parte). En F. Espósito, A. García Orsi, G. Schinca y L. Sesnich (eds.), El naturalismo en la prensa porteña: Reseñas y polémicas sobre la formación de la novela nacional (1880-1892) (pp. 29-34). La Plata: Universidad Nacional de La Plata. E-book disponible en http://www.memoria.fahce.unlp.edu.ar/libros/pm.24/pm.24.pdf. 